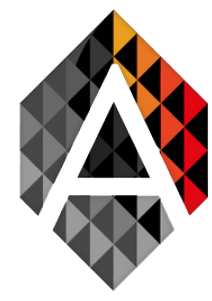

\title{
Efficiency, profitability and productivity: Technological applications in the agricultural sector
}

\author{
María E. Pérez-Pons ${ }^{a}$, Javier Parra-Dominguez ${ }^{\mathrm{a}}$, Marta \\ Plaza $^{\mathrm{a}}$, Pablo Chamoso ${ }^{\mathrm{a}, \mathrm{b}}$ and Ricardo S. Alonso ${ }^{\mathrm{a}, \mathrm{b}}$ \\ a BISITE Research Group, University of Salamanca, Edificio Multiusos I+D+i, Calle \\ Espejo, 2, 37007, Salamanca (Spain) \\ b AIR institute, IoT Digital Innovation Hub, Edificio Parque Científico, Módulo 305, Paseo \\ de Belén, 11, Campus Miguel Delibes, 47011, Valladolid (Spain) \\ eugenia.perez@usal.es; javierparra@usal.es; chamoso@usal.es; marta.plaza@usal.es; \\ ralorin@usal.es
}

$\begin{array}{ll}\text { KEYWORD } & \text { ABSTRACT } \\ \begin{array}{ll}\text { Efficiency; Agri- } \\ \text { tech; Precision }\end{array} & \begin{array}{l}\text { New technological advances have made it possible to improve precision and } \\ \text { efficine consumption of natural resources. This article presents a series }\end{array} \\ \begin{array}{l}\text { Agriculture; } \\ \text { of different use cases in which technology has benefited peripheral and cross- }\end{array} & \begin{array}{l}\text { border areas and continues to do so. Real-scenario implementations of cutting- } \\ \text { Learning. }\end{array} \\ & \begin{array}{l}\text { edge Internet of Things (IoT) technologies have been conducted in Portugal } \\ \text { technological applications on the regions and the production efficiency. }\end{array}\end{array}$

\section{Introduction}

Agriculture has been a growth lever for the economy at all levels, as well as one of the industries with the highest contribution to world GDP (Garibaldi et al., 2019). Agriculture has always been key to the development of any region, Loizou et al (2019) demonstrated that the agriculture is a driver of growth in any region. Nowadays, the information era has made it possible to integrate technological advances in agriculture (Zhang et al. 2002). Agricultural production systems have benefited from the incorporation of technological developments which had initially been targeted at other industries. Precision Agriculture (PA) is conceptualized as a systemic approach to reorganizing the entire farming system towards low input, high efficiency and sustainable agriculture (Cox et al., 2002). This new approach benefits primarily from the emergence and convergence of several technologies, including

María E. Pérez-Pons, Javier Parra-Dominguez, Marta Plaza, Pablo Chamoso and Ricardo S. Alonso Efficiency, profitability and productivity: Technological applications in the agricultural sector
ADCAIJ: Advances in Distributed Computing and Artificial Intelligence Journal Regular Issue, Vol. 9 N. 4 (2020), 47-54 eISSN: 2255-2863 - https://adcaij.usal.es Ediciones Universidad de Salamanca - CC BY-NC-ND 
Global Positioning Systems (GPS), Geographic Information Systems (GIS), miniaturized computer components, automatic control, detection in the field and remote sensing, mobile computing, advanced information processing and telecommunications (Gibbons., 2000).

In the current ecosystem, technological innovation doesn't cease, and new paradigms emerge, such as the Edge Computing paradigm (Satyanarayanan., 2017). Edge Computing is one of the latest technologies to have contributed to agriculture, making it possible to monitor data without having to bear the expenses of real-time data storage (Sittón-Candanedo et al., 2019). Edge computing brings the processing power as close as possible to where the data is being generated. In other words, it consists in bringing the cloud closer to the edge of the network. This leads to lower data traffic from the sensors to the cloud, which is important in PA where the different sensors are collecting data constantly. Throughout the years different authors have devised different technological contributions and architectures for different environments, and particularly the most recent ones in the Agricultural Industry such as that presented by Alonso et al (2011).

\subsection{Efficiency and profitability}

At this point it is interesting to observe the connection that efficiency and profitability have with productivity. Production process efficiency is understood as the adoption of measures or technologies that allow for inputs reduction or outputs maximization, however, this is not so simple, as represented by Farrell et al (1957). The use of new equipment (Dominguez et al., 2015) and technologies makes it difficult to attribute or identify what leads to efficiency and, therefore, profitability (Färe et al., 2013).

In the case of agribusiness, increases in efficiency are traditionally linked to an improvement in environmental conditions as mentioned previously. In addition, there is a clear connection between the reduction of inputs through the use of technologies and the improvements in productivity, Pérez-Pons, M. E., Plaza-Hernández, M., Alonso, R. S., Parra-Domínguez, J., \& Prieto, J. (2021). Increasing Profitability and Monitoring Environmental Performance: A Case Study in the Agri-Food Industry through an Edge-IoT Platform. Sustainability, 13(1), 283. https://www.mdpi.com/2071-1050/13/1/283.

The link to which one wants to reach goes beyond the one studied with respect to work and profitability (Dominguez et al., 2015) and a broad paradigm studied in agriculture as it depends mainly at physical labor.

This article collects different examples of how new technologies affect and contribute to a more efficient agriculture in different border and cross-border areas. Regarding the applications of new technologies, one of the fundamental parts that will be covered in this article, is the analysis of the information and the data to make predictions and also to gather information to have a more complete view of each scenario and particular case.

This article has been structured as follows: In Section 2 an introduction to the AgTech concept is provided, Section 3 describes different technologies and process that are mostly used in Agriculture and technological innovations, in Section 4 different use cases in Spain are presented as examples of successful technological applications in agriculture, and finally sections 5 and 6 summarize the opportunities that new technologies offer and draw conclusions from this article.

\section{Ag-Tech}

In recent years, information management and IoT (Internet of Things) technology have developed rapidly and have broader applications. Over the last few years, several experiments have addressed the

María E. Pérez-Pons, Javier Parra-Dominguez, Marta Plaza, Pablo Chamoso and Ricardo S. Alonso Efficiency, profitability and productivity: Technological applications in the agricultural sector
ADCAIJ: Advances in Distributed Computing and Artificial Intelligence Journal Regular Issue, Vol. 9 N. 4 (2020), 47-54 eISSN: 2255-2863 - https://adcaij.usal.es Ediciones Universidad de Salamanca - CC BY-NC-ND 
use of IoT and the collection of data by different sensors in agricultural facilities and real agricultural production scenarios (Zhao et al., 2010).

The term agri-tech or "Ag-Tech" defines the different applications of digital technology to agriculture, it includes a wide variety of new technologies that are being applied to agricultural systems, increasing productivity, efficiency and profitability. As shown in Fig 1, different technologies can be combined within the Ag-tech environment.

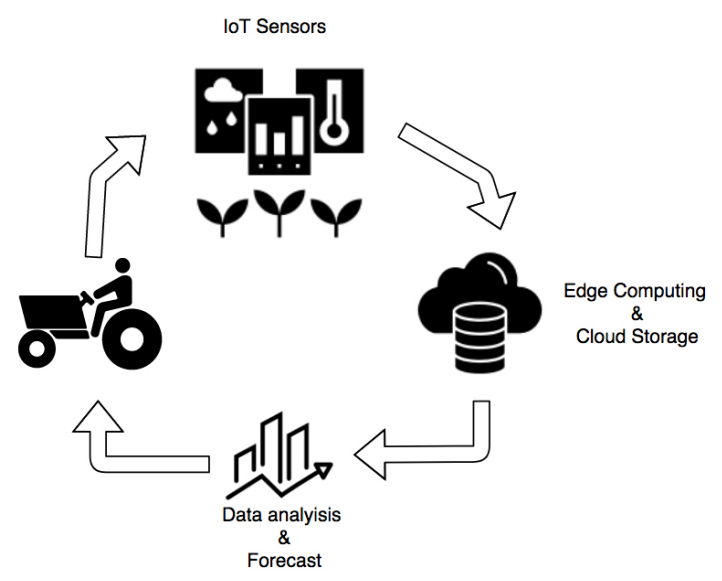

Figure 1. Ag-Tech Process Diagram. Font: Elaborated by the authors.

In the 20th century, the technologies used to collect remote sensing information changed from visual observations of airborne individuals, to cameras mounted on airplanes, high resolution satellites, digital sensors mounted on unmanned aerial vehicles. Furthermore, the use of unmanned aviation for crop surveillance began experimentally in the early 21st century (Mulla et al., 2013).

\subsection{Technologies in Ag-tech}

New technologies that could benefit PA emerge every day. Different cutting-edge technologies are presented and tested to enhance agriculture. Nevertheless, not only technological innovations are important but also the degree to which their implementation in real scenarios is feasible. Lidblom et al (2013) made a literature review design and development as the determinant factors in the adoption of technology. In a paper presented by Rossi et al (2014), the cost is described as one of the challenges faced by farmers implementing Decision Support Systems in a real scenario (vineyards). The costs of implementation can be even higher in some regions due to the lack of connectivity, which means that are not only technological limitations but also environmental ones. De Miguel et al (2014) described the challenges faced by remote regions which are not only related to access to technology but also to other socio-economic factors.

Bhakta et al (2019) carried out a systematic review in which they identified the different advances to date in relation to the application of these technologies in agriculture. The authors grouped these technologies according to three key components:

- Data collection

- Data analysis

- Control of the variable rate.

María E. Pérez-Pons, Javier Parra-Dominguez, Marta Plaza, Pablo Chamoso and Ricardo S. Alonso Efficiency, profitability and productivity: Technological applications in the agricultural sector
ADCAIJ: Advances in Distributed Computing and Artificial Intelligence Journal Regular Issue, Vol. 9 N. 4 (2020), 47-54 eISSN: 2255-2863 - https://adcaij.usal.es Ediciones Universidad de Salamanca - CC BY-NC-ND 
In smart agriculture, real-time analysis is very crucial for sustainable development, which is why the study focused on it. The technologies used in agricultural decision-making were examined to discover new lines of research in agricultural data analysis. This helped develop a dynamic decision support system which analyzed large amounts of agricultural data in real time. Finally, different variable-rate technologies were studied and compared (Bhakta et al., 2019).

Regardless of the country, PA policies help use resources efficiently (Say et al., 2018). Table 1 describes the main technologies used in PA that Say et al. (2018), developed to bring together the main variables that should be monitored and that had a direct impact on PA.

Table 1. Technologies used in PA. Source: Table adapted from Say et al. (2018).

\begin{tabular}{ccc}
\hline Data collection & Data analysis & Control of variabilities \\
\hline Soil sampling and mapping & $\begin{array}{c}\text { Geographic information } \\
\text { systems (GIS) }\end{array}$ & Section controls \\
\hline $\begin{array}{c}\text { Performance monitoring } \\
\text { Global positioning by } \\
\text { satellite }\end{array}$ & Agricultural mapping software & $\begin{array}{c}\text { Guides based on global } \\
\text { navigation satellite system }\end{array}$ \\
\hline Remote sensing & Geostatistics & Automated robots \\
\hline Field / crop exploration & Edge-Computing & \\
\hline
\end{tabular}

\section{Use cases}

This Section discusses studies conducted in real scenarios, in which technological applications have been developed and tested under a complete PA framework or logistics chain framework. This Section focuses in particular on the real-life case studies conducted in Spain and also in Portugal. Spain and Portugal are countries in which agriculture plays an important role, and that is why there is an increasing number of use cases in which agriculture and technology converge.

In today's interconnected society, it is important that all the agents involved in agriculture can work in the most efficient way possible thanks to technological innovations. In the literature, there is a range of relevant crop and livestock monitoring systems. Among the different examples, hereby are presented, three have used technological solutions from the monitoring of the crops and in the logistics chain for monitoring cold products to ensure that they are still fit for use or consumption.

The first example is the use case of Olivares in southern Spain in which the effects of PA have been studied, as well as its real impact on resource efficiency. In this study, the variability of five variables had been measured, namely; the crops, the homogeneous areas within the farm and the nutrient composition of the crops (Álamo et al., 2012).

In the same line, the second example also tracked the crops and also the livestock. Alonso et al (2020), presented an architecture for the monitoring of crops and also livestock, with the use of Edge-Computing technologies. They deployed a platform in a real scenario demonstrating that the

María E. Pérez-Pons, Javier Parra-Dominguez, Marta Plaza, Pablo Chamoso and Ricardo S. Alonso Efficiency, profitability and productivity: Technological applications in the agricultural sector
ADCAIJ: Advances in Distributed Computing and Artificial Intelligence Journal Regular Issue, Vol. 9 N. 4 (2020), 47-54 eISSN: 2255-2863 - https://adcaij.usal.es Ediciones Universidad de Salamanca - CC BY-NC-ND 
implementation of Edge Computing contributes to a reduction in data traffic and an improvement in the communications between the IoT-Edge layers and the cloud.

Finally, Chandra et al (2014) presented a IoT-based proposal for monitoring that applies to both the logistics chain and agriculture. The logistics chain is crucial at all levels, and for instance, in that research they analyze a refrigerated truck between Spain and France. As part of the agriculture we can consider also the part of cold chain, so all the advantages that are developed in terms of technological applications in the production phases, can also be efficient within the logistics phase.

Another country bordering with Spain is Portugal which is also undergoing many advances and applications in IoT and Agri-tech. The agricultural sector in Portugal is also becoming increasingly significant for the country's economy, which has led researchers to seek solutions for efficient farming. The results of the study on small-scale soil variation and its effect on pasture yield in southern Portugal show that the relative elevation of the field has a significant influence on the dynamics of soil nutrients and, consequently, on the variability of pasture yield. Furthermore, they demonstrated that in shallow Mediterranean soils, the relative elevation of the field affects the spatial distribution of soil moisture content and the depth of the bedrock, determining factors in the dry matter yield of pastures (2013).

\section{The future of technology and technological challenges in the agricultural sector}

Technology permits to transform the human environment in order to adapt it to human needs. Technology is undergoing continuous progress and so are its applications in different fields. The third Industrial revolution, also called Third Technological Revolution, which was a concept proposed by Riftkin (2011) and then endorsed by the European Parliament in 2006 (Rifkin., 2011), was presented as a potential possible solution to the energy and economic crisis.

The different applications of technology in a wide range of fields have made it possible in recent years to improve efficiency in different sectors. However, the possibility of implementing PA measures and being able to benefit from technology is correlated with the technological capabilities of each society. The concept of PA consists of a management strategy that collects, processes and analyzes different types of data such as temporal, spatial and individual and combines them with other information to support management decisions according to the estimated variability, and thus improve the efficiency in the use of resources and productivity. In this projection of estimated variability, in some cases it consists of the application of artificial intelligence.

For this reason, it must also be taken into account that there are some social challenges that create obstacles to adopting the concept of PA in developing countries, where the majority are small-scale farms and fragmented lands with several owners. Salam et al (2019), presented a potential roadmap in the field of PA in which the communications and sensing will play a key role in the transformation of that industry. The heterogeneity of cropping systems, as well as the lack of experts, knowledge and technical participation, and numerous market imperfections are just some of those obstacles.

Within technology there are many fields of research and application of research such as the nanotechnology. The revolution of nanotechnology in agriculture is a reality. Bajali et al (2019) made a survey to identify the latest publications considering the applications of technology in different industries, being the agricultural industry one of the topics that has raised also an interesting number of articles in the field of technological applications. Nanotechnology is an interesting line of research for the future and it will be vital in transforming agriculture into a more efficient, sustainable and resilient sector. On

María E. Pérez-Pons, Javier Parra-Dominguez, Marta Plaza, Pablo Chamoso and Ricardo S. Alonso Efficiency, profitability and productivity: Technological applications in the agricultural sector
ADCAIJ: Advances in Distributed Computing and Artificial Intelligence Journal Regular Issue, Vol. 9 N. 4 (2020), 47-54 eISSN: 2255-2863 - https://adcaij.usal.es Ediciones Universidad de Salamanca - CC BY-NC-ND 
the other hand, Abdullah and Samah (2013) identified the factors that influence the use of agricultural technology by farmers.

In the agri-industry, every day new challenges are emerging. Different authors such as Duhnan et al (2017) and Bajali et al (2019), present different and interesting approaches through the nanotechnology reality. Duhnan et al (2017) presents the reality of how nanotechnology can already improve traditional agriculture and all the potential in terms of biology and its technological application. Lowri et al (2019) presented different approaches that are interesting within the possibilities offered by technology and more particularly nanotechnology.

\section{Conclusions}

This article has reviewed the main technological applications in the field of agriculture, as well as the different use cases conducted in real scenarios. Leading to the conclusion that there is a wide range of technological applications in agriculture and it will continue to broaden in the coming years, covering countless areas, such as innovation in pesticides to IoT applications. All of these measures lead to improved efficiency, sustainability and economic growth. The collected data, research into the agricultural industry and the impacts of new technologies have led us to interesting conclusions;

- The use of technologies in the agricultural sector has a positive impact on the sustainability and the economy because data collection helps develop more efficient solutions that have a lower environmental impact in terms of the use of natural resources.

- The technological development of each society affects its ability to adopt technology in the agriculture sector; the more societies develop technologically the more interconnected is our world and technological applications reach different sectors, making them efficient.

- New technologies such as Edge Computing will make it possible to continue reducing costs and make the whole data processing process more efficient. In addition, they make it possible to continue monitoring when unexpected connection failures arise.

Future lines of research will focus on examining and evaluating the impact of large-scale technological implementations and on coming up with innovative solutions that would make large-scale implementations truly useful in a several sectors. Since large-scale implementations remain one of the main problems in many occasions for the implementation of improvements in many occasions. It will also be interesting to see how Edge Computing will contribute to all these implementations. Since it is a paradigm in which there is still a long way to go and that it is going to be a very important change in the IoT.

\section{Acknowledgements}

This work has been partially supported by the European Regional Development Fund (ERDF) through the Interreg Spain-Portugal V-A Program (POCTEP) under grant 0631_DIGITEC_3_E (Smart growth through the specialization of the cross-border business fabric in advanced digital technologies and blockchain.).

María E. Pérez-Pons, Javier Parra-Dominguez, Marta Plaza, Pablo Chamoso and Ricardo S. Alonso Efficiency, profitability and productivity: Technological applications in the agricultural sector
ADCAIJ: Advances in Distributed Computing and Artificial Intelligence Journal Regular Issue, Vol. 9 N. 4 (2020), 47-54 eISSN: 2255-2863 - https://adcaij.usal.es Ediciones Universidad de Salamanca - CC BY-NC-ND 


\section{References}

Abdullah, F. A., \& Samah, B. A. (2013). Factors impinging farmers' use of agriculture technology. Asian Social Science, 9(3), 120.

Álamo, S., Ramos, M. I., Feito, F. R., \& Cañas, A. (2012). Precision techniques for improving the management of the olive groves of southern Spain. Spanish Journal of agricultural research, (3), 583-595.

Alonso, R. S., Sittón-Candanedo, I., García, Ó., Prieto, J., \& Rodríguez-González, S. (2020). An intelligent Edge-IoT platform for monitoring livestock and crops in a dairy farming scenario. Ad Hoc Networks, 98, 102047.

Alonso, R. S., Tapia, D. I., \& Corchado, J. M. (2011). Sylph: A platform for integrating heterogeneous wireless sensor networks in ambient intelligence systems. International Journal of Ambient Computing and Intelligence (IJACI), 3(2), 1-15.

Ashraf, C. K. (2012). The relationship between working capital efficiency and profitability. Advances in management.

Balaji, S., Nathani, K., \& Santhakumar, R. (2019). IoT technology, applications and challenges: a contemporary survey. Wireless personal communications, 108(1), 363-388

Bhakta, I., Phadikar, S., \& Majumder, K. (2019). State-of-the-art technologies in precision agriculture: a systematic review. Journal of the Science of Food and Agriculture, 99(11), 4878-4888.

Chandra, A. A., \& Lee, S. R. (2014). A method of WSN and sensor cloud system to monitor cold chain logistics as part of the IoT technology. International Journal of Multimedia and Ubiquitous Engineering, 9(10), 145-152.

Cox, S. (2002). Information technology: the global key to precision agriculture and sustainability. Computers and electronics in agriculture, 36(2-3), 93-111.

De Miguel Hidalgo, A., Parra Domínguez, J. \& Benzinho, J.M. (2014). Costes de Contexto Tranfronterizos en el ámbito Empreserial- Territorio BIN-SAL (p.183). Diputación de Salamanca: OAEDER.

Domínguez, J. P., Sánchez, I. M. G., \& Domínguez, L. R. (2015). Relationship between police efficiency and crime rate: a worldwide approach. European Journal of Law and Economics, 39(1), 203-223.

Duhan, J. S., Kumar, R., Kumar, N., Kaur, P., Nehra, K., \& Duhan, S. (2017). Nanotechnology: The new perspective in precision agriculture. Biotechnology Reports, 15, 11-23.

Färe, R., Grosskopf, S., \& Lovell, C. K. (2013). The measurement of efficiency of production (Vol. 6). Springer Science \& Business Media.

Farrell, M. J. (1957). The measurement of productive efficiency. Journal of the Royal Statistical Society: Series A (General), 120(3), 253-281.

Garibaldi, L. A., \& Pérez-Méndez, N. (2019). Positive outcomes between crop diversity and agricultural employment worldwide. Ecological Economics, 164, 106358.

Gibbons, G. (2000). Turning a farm art into science-an overview of precision farming. URL: https:// www.precisionfarming.com.

Lindblom, J., Lundström, C., Ljung, M., \& Jonsson, A. (2017). Promoting sustainable intensification in precision agriculture: review of decision support systems development and strategies. Precision Agriculture, 18(3), 309-331.

Loizou, E., Karelakis, C., Galanopoulos, K., \& Mattas, K. (2019). The role of agriculture as a development tool for a regional economy. Agricultural Systems, 173, 482-490.

María E. Pérez-Pons, Javier Parra-Dominguez, Marta Plaza, Pablo Chamoso and Ricardo S. Alonso Efficiency, profitability and productivity: Technological applications in the agricultural sector
ADCAIJ: Advances in Distributed Computing and Artificial Intelligence Journal Regular Issue, Vol. 9 N. 4 (2020), 47-54 eISSN: 2255-2863 - https://adcaij.usal.es Ediciones Universidad de Salamanca - CC BY-NC-ND 
Lowry, G. V., Avellan, A., \& Gilbertson, L. M. (2019). Opportunities and challenges for nanotechnology in the agri-tech revolution. Nature nanotechnology, 14(6), 517-522.

Mulla, D.J. 2013. Twenty five years of remote sensing in precision agriculture: Key advances and remaining knowledge gaps. Biosyst. Eng. 114:358-371.

Rifkin, J. (2011). The third industrial revolution: how lateral power is transforming energy, the economy, and the world. Macmillan.

Rossi, V., Salinari, F., Poni, S., Caffi, T., \& Bettati, T. (2014). Addressing the implementation problem in agricultural decision support systems: the example of vite. net ${ }^{\circledR}$. Computers and Electronics in Agriculture, 100, 88-99.

Salam, A., \& Shah, S. (2019, April). Internet of things in smart agriculture: Enabling technologies. In 2019 IEEE 5th World Forum on Internet of Things (WF-IoT) (pp. 692-695). IEEE.

Satyanarayanan, M. (2017). The emergence of edge computing. Computer, 50(1), 30-39.

Say, S. M., Keskin, M., Sehri, M., \& Sekerli, Y. E. (2018). Adoption of precision agriculture technologies in developed and developing countries. Online J. Sci. Technol, 8(1), 7-15.

Serrano, J. M., Shahidian, S., \& da Silva, J. R. M. (2013). Small scale soil variation and its effect on pasture yield in southern Portugal. Geoderma, 195, 173-183.

Sittón-Candanedo, I., Alonso, R. S., Corchado, J. M., Rodríguez-González, S., \& Casado-Vara, R. (2019). A review of edge computing reference architectures and a new global edge proposal. Future Generation Computer Systems, 99, 278-294.

Stafford, J. V. (2000). Implementing precision agriculture in the 21st century. Journal of Agricultural Engineering Research, 76(3), 267-275.

Zhang, N., Wang, M., \& Wang, N. (2002). Precision agriculture-a worldwide overview. Computers and electronics in agriculture, 36(2-3), 113-132.

Zhao, J. C., Zhang, J. F., Feng, Y., \& Guo, J. X. (2010, July). The study and application of the IOT technology in agriculture. In 20103 rd International Conference on Computer Science and Information Technology (Vol. 2, pp. 462-465). IEEE.

María E. Pérez-Pons, Javier Parra-Dominguez, Marta Plaza, Pablo Chamoso and Ricardo S. Alonso Efficiency, profitability and productivity: Technological applications in the agricultural sector
ADCAIJ: Advances in Distributed Computing and Artificial Intelligence Journal Regular Issue, Vol. 9 N. 4 (2020), 47-54 eISSN: 2255-2863 - https://adcaij.usal.es Ediciones Universidad de Salamanca - CC BY-NC-ND 